\title{
Generational effects and gender height dimorphism in contemporary Spain
}

\author{
Joan Costa-Font ${ }^{\mathrm{a}, \mathrm{b}, *}$, Joan Gil $^{\mathrm{b}}$ \\ ${ }^{\text {a }}$ LSE Health and European Institute, London School of Economics, London, UK \\ ${ }^{\mathrm{b}}$ Departament de Teoria Econòmica and CAEPS, Universitat de Barcelona, Catalonia, Spain
}

Received 15 October 2007; accepted 15 October 2007

\begin{abstract}
We examine the influence of socio-environmental (and birth cohort specific) effects on both adult height and gender dimorphism (height gap). Our data set is from contemporary Spain, a country governed by an authoritarian regime for about 40 years. Both OLS and quantile regression approaches are used to examine these patterns. Furthermore, we then draw upon a Blinder-Oaxaca decomposition approach to explain the influence of socio-political environment in explaining gender dimorphism. Our findings point to a significant increase in adult height in the generations that benefited from the country's economic liberalization in the 1950s, and especially among those brought up after the transition to democracy in the 1970s. In contrast, individual heterogeneity suggests that only in recent generations has "height increased more among the tallest". We also find that the effects of education on height are greater among shorter individuals. Although the mean gender difference in height is $11.7 \mathrm{~cm}$, birth cohort and capabilities effects along with other controls explain on average roughly $4 \%$ of the gender height dimorphism, irrespective of the quantile considered. (C) 2007 Elsevier B.V. All rights reserved.
\end{abstract}

JEL classification: I19; N44; N84

Keywords: Adult height; Generational effects; Individual heterogeneity; Gender discrimination; Sexual dimorphism; Quantile regression; Blinder-Oaxaca decomposition; Spain; Physical stature; Anthropometry

\section{Introduction}

Height is a retrospective measure of an individual's health and biological standard of living, almost completely determined before the person reaches the age of 20 (Komlos and Baten, 1998; Persico et al., 2004). In a genetically stable society changes in adult height is a physical return to

\footnotetext{
* Corresponding author at: European Institute, London School of Economics, Houghton Street, WC2A 2AE London, UK. E-mail address: j.costa-font@1se.ac.uk (J. Costa-Font).
} 
psychologically and socio-economically favorable environments (Steckel, 1995). If so, beneficial inputs such as nutritional improvements, comprehensive health care, health awareness and suitable housing conditions may all potentially translate into height improvements for those at growing ages (Komlos and Lauderale, 2007; Smith et al., 2003; WHO, 1983). More recently, some studies estimate that environmental factors are responsible for as much as $20 \%$ of adult height variability (Silventoinen, 2003). ${ }^{1}$ Some suggest that the development of the welfare state influenced height growth (Sunder, 2003). Accordingly, the average height stagnation of the American population during much of the second half of the 20th century could be well explained in part by the fragmentation of the health system along with other nutritional and environmental effects (Komlos and Baur, 2004; Komlos and Lauderale, 2007).

Environmental pathways are often generation specific and include inter-alia medical services, nutrition, lifestyle attributes such as fast food culture and welfare support for health and social care after controlling for individual heterogeneity (e.g., capacity, geography). ${ }^{2}$ The political system also matters insofar as it determines to considerable extent the institutional framework within which the economic actors manage their lives (North, 1991). Autocratic regimes-such as Spain during the fascist era - in which essential liberties are denied and international economic exchange is restricted - would be expected to curtail health production.

The introduction of structural reforms in a country's organization (e.g., the transition from planned to market economies) might induce environmentally healthy effects and ultimately enhance a positive affect on well being in the long run. However, the effects of economic and political liberalization on height do not necessarily go hand in hand (Olson, 1993). Whilst economic liberalization may bring reforms that improve access to food sources, introduction of new technologies and so on, some studies find that the main effects on human capital come from political liberalization and the introduction of democratic decision-making systems (Tavares and Wacziarg, 2001). ${ }^{3}$

To be sure, some people are deprived in democracies as well. We hypothesize that economic liberalization might increase height faster among groups deprived in earlier generations. On the other hand, political liberalization would be expected to convey these effects to the entire population. Furthermore, certain institutional environments are hypothetically more damaging to women than to men. Traditional explanations for gender (sex) height dimorphism in mammals include evolutionary explanations relying primarily on sexual selection ${ }^{4}$ and mating (Bogin, 1999; Darwin, 1871). However, humans appear to exhibit lower levels of sexual dimorphism than other species and, such dimorphism appears to decrease with evolution (Bonduriansky, 2007). ${ }^{5}$

\footnotetext{
${ }^{1}$ Environmental factors affect dimensions of health and well-being such as the quality of parental care, human safety, access to food and nourishment, social recognition and teenage autonomy as well as economic barriers to leisure activities-all factors that affect height.

${ }^{2}$ For instance, some contemporary evidence suggests that shorter individuals are more likely to be discriminated against (Frieze et al., 1990). However, Case and Paxson (2006) question this view, saying that height might reflect the influence of "omitted variable biases", most notably the influence of strength and intellectual capacity. They argue that, when the empirical height specification accounts for differences in individuals' intellectual and physical capacity, the effect of height on wages disappears.

${ }^{3}$ Indeed, while political liberalization is assumed to involve those individuals who uphold democratic values in collective decision-making, economic liberalization refers solely to the areas of economic activity and commerce.

${ }^{4}$ Sexual mating explained why males are largers and increasing levels of monogamy in humans might explain reduction in sexual competition and resulting adaptation.

${ }^{5}$ Rogers and Mukherjee (1992) present data that indicate that in human societies, men are larger than women by roughly $10 \%$.
} 
On the other hand, even if environmental influences have empirical support (Wolf and Gray, 1982), some evolutionary theories suggest that it is inversely related to the degree of paternal investment in parenting (Bonduriansky, 2007). Explanations include the existence of unfair social norms (known as 'environmental disadvantages') and to disadvantages in the treatment of hazards at childbirth and in gaining access to food. The influence of some of these factors has been pointed out in the feminist economics literature, namely the effects of individual ability (Iversen, 2003) and women's self-respect compared to men (Nussbaum, 2003, 2004). However, the evidence to explain patterns of adult height differences between males and females is limited.

Using data from the Spanish National Health Survey (2003), we examine the determinants of physical stature for adult men and women in contemporary Spain, given the significant sociopolitical and economic reforms that have taken place in the last three decades. We consider birth cohort environmental effects on (i) self-reported adult height and its distribution (individual heterogeneity) and (ii) the gender dimorphism and its distribution in different height quantiles, providing information on the effect of individual heterogeneity. By individual heterogeneity we mean unobserved factors that could influence the casual inferences on the determinants of individual height. Some if these effects could well be genetic effects, as well as unmeasured ability and other potentially relevant covariates.

\section{Brief background of Spain 1920-2000}

Spain is an interesting setting for the examination of changes in adult height because of the institutional and environmental reforms implemented. Overall, in half a century Spain has evolved from underdevelopment and authoritarianism to prosperity and democracy. The country's economic and socio-political reforms included economic liberalization after two decades of autarky (1939-1959) - and the subsequent reforms that introduced economic rights but especially the effects of the political transition from an authoritarian regime to a parliamentary democracy in the late 1970s and the development of the Welfare State, though the first attempts date back to the introduction of social health insurance for low-salaried workers during the era of the Second Republic (1931-1936).

After the upheavals of the early 20th century, with a dictatorship lasting most of the 1920s, Spain was proclaimed a Republic in 1931, for the second time in its history. The Republic was challenged by large-scale but unsuccessful uprisings in 1932 and 1934. The ensuing notorious Civil War (1936-1939) ended in victory for the military insurgents and led to 40 years of dictatorship. The resulting devastation was so marked that Spain's economy did not recover prewar GDP levels (1929) in absolute terms until 1951. Exile that followed after the Civil War implied a significant loss of already limited human capital, especially those of younger ages.

Under the new regime the majority of the population lacked basic liberties, a fact which may well have influenced access to health production inputs. Indeed, the post-civil-war period was marked by brutal repression, exile for many, and a shattered economy. The dictatorship enforced a system of autarkic industrialization in an attempt to be self-sufficient, but the system collapsed within a decade due to severe imbalances in the country's trade and finances and to social divisions. ${ }^{6}$ In 1959, as a result of changes in the government, an economic reform was introduced

\footnotetext{
${ }^{6}$ The social repression took the form of the imposition of rigid social norms based on conservative Catholic values, especially in schools. At that time, Spain lagged behind most Western countries in terms of living standards, industrial expansion, and employment growth.
} 
known as the Stabilization Plan (designed in cooperation with the International Monetary Fund) which built on previous agreements undertaken with the United States (US) government after 1951. At the macroeconomic level, this change of direction resulted in an average income growth rate $1960-1975$ of $6.5 \%$, the highest in the Western world after Japan, and had a pronounced effect on the patterns of consumption (García Delgado and Jiménez, 1999). Reforms in welfare provision were introduced, primarily in health and income replacement insurance after the approval of the Social Security Act of 1967 which set up the basis of health and social security system, with the development of a publicly funded network of primary and specialized outpatient care (Duran et al., 2006).

In the last years of the dictatorship, Spain obtained a preferential agreement with the European Community. After the death of Franco, a new Spanish Constitution was introduced in 1978, and a set of political and economic reforms were put in place, including the recognition of the right of all Spaniards to public health care services. The democratization of the country led to the creation of new institutions, in particular the progressive introduction of new values in schools and the development of the reforms that gave rise to a welfare state and decentralization of social policy responsibilities (López-Casasnovas et al., 2005), especially after the General Health Act of 1986. Furthermore, economic liberalization led to the creation of the social insurance system to cover health care during the late 1960s, whereas the set up of a National Health System (NHS) can be directly attributed to the democratization process of the mid-1980s. However, the prevailing institutional inertia slowed the implementation of these plans, and consequently the changes took place progressively rather than immediately. Since 1986 Spain is a member of the European Union. In the so called "golden age" (1950-1974) GDP per capita rose seven times more rapidly than during the previous hundred years (1850-1950), namely 5.9\%, from 1974-1986 growth slowed to $1.8 \%$ and then again it expanded to $3.3 \%$ after 1986 (Prados, 2006).

\section{Data and methods}

\subsection{Database and variables}

We use data from the Spanish National Health Survey (SNHS) $2003,^{7}$ a nationwide crosssection survey which gathers information on the population's perception of their state of health, primary and specialized health care utilization, consumption of medicines, aspects of lifestyle (alcohol consumption, smoking, food, etc.), habits related to risk factors, anthropometric characteristics, preventive practices and socio-economic characteristics. The SNHS (2003) follows a stratified multistage sampling procedure in which the primary strata are the Autonomous Communities and sub-strata are then defined according to population size in particular areas. Within the sub-strata, municipalities and sections (primary and secondary sampling units, respectively) are selected using a proportional random sampling scheme. Individuals are randomly selected from the sections. The survey provides weighting factors to raise the estimations to the national level. ${ }^{8}$

Because the data on physical stature is self-reported (in centimeters, without shoes), a reporting bias might arise. The literature acknowledges the existence of overestimation of height that vary with individuals' age and gender (Giles and Hutchinson, 1991; Hill and Roberts, 1998;

\footnotetext{
${ }^{7}$ http://www.ine.es/jaxi/menu.do?type $=$ pcaxis $\&$ path $=\% 2 \mathrm{Ft} 15 \% 2 \mathrm{Fp} 419 \&$ file $=$ inebase $\& \mathrm{~L}=1$.

${ }^{8}$ The survey is conducted every 2 years.
} 
Table 1

Variables and definitions $(N=15,396)$

\begin{tabular}{|c|c|c|c|}
\hline Variables & Definition & Mean & S.D. \\
\hline \multicolumn{4}{|l|}{ Birth cohort } \\
\hline$<1920$ & $=1$ if the adult was born before $1920 ; 0$ otherwise. & 0.0232 & 0.151 \\
\hline $1920-1929$ & $=1$ if the adult was born between 1920 and $1929 ; 0$ otherwise. & 0.0851 & 0.279 \\
\hline $1930-1939$ & $=1$ if the adult was born between 1930 and $1939 ; 0$ otherwise. & 0.1207 & 0.326 \\
\hline $1940-1949$ & $=1$ if the adult was born between 1940 and $1949 ; 0$ otherwise. & 0.1287 & 0.335 \\
\hline $1950-1959$ & $=1$ if the adult was born between 1950 and $1959 ; 0$ otherwise. & 0.1622 & 0.369 \\
\hline $1960-1969$ & $=1$ if the adult was born between 1960 and $1969 ; 0$ otherwise. & 0.2070 & 0.405 \\
\hline $1970-1979$ & $=1$ if the adult was born between 1970 and $1979 ; 0$ otherwise. & 0.2108 & 0.408 \\
\hline $1980-1984$ & $=1$ if the adult was born since 1980 and $1984 ; 0$ otherwise. & 0.0621 & 0.241 \\
\hline \multicolumn{4}{|c|}{ Capabilities (strength intellectual capacity, etc.) } \\
\hline Equivalent income & Equivalent net monthly household income (in Euros) & 786.30 & 462.37 \\
\hline Unschooled & $=1$ if the adult is unschooled or illiterate; 0 otherwise. & 0.1452 & 0.352 \\
\hline Primary education & $=1$ if the adult completed primary education; 0 otherwise. & 0.3157 & 0.465 \\
\hline Secondary education & $=1$ if the adult completed secondary education; 0 otherwise. & 0.3305 & 0.470 \\
\hline University education & $=1$ if the adult completed university education; 0 otherwise. & 0.2086 & 0.406 \\
\hline \multicolumn{4}{|c|}{ Ethnicity and nationality controls } \\
\hline Spanish & $=1$ if the adult is of Spanish nationality; 0 otherwise. & 0.9688 & 0.174 \\
\hline Euro-North American & $\begin{array}{l}=1 \text { if the adult is of European or North American } \\
\text { nationality; } 0 \text { otherwise. }\end{array}$ & 0.0091 & 0.095 \\
\hline South-American & $\begin{array}{l}=1 \text { if the adult is of Latin American nationality; } \\
0 \text { otherwise. }\end{array}$ & 0.0160 & 0.126 \\
\hline Asian-Oceania & $\begin{array}{l}=1 \text { if the adult is of Asian or Oceanian nationality; } \\
0 \text { otherwise. }\end{array}$ & 0.0018 & 0.042 \\
\hline African & $=1$ if the adult is of African nationality; 0 otherwise. & 0.0042 & 0.065 \\
\hline \multicolumn{4}{|l|}{ Geographical controls } \\
\hline Village & $\begin{array}{l}=1 \text { if the adult lives in a town with less than } 10 \\
\text { thousand inhabitants; } 0 \text { otherwise. }\end{array}$ & 0.2545 & 0.436 \\
\hline Town & $\begin{array}{l}=1 \text { if the adult lives in a town with between } 10 \\
\text { and } 100 \text { thousand inhabitants; } 0 \text { otherwise. }\end{array}$ & 0.3568 & 0.479 \\
\hline City & $\begin{array}{l}=1 \text { if the adult lives in a town with between } 100 \\
\text { and } 400 \text { thousand inhabitants; } 0 \text { otherwise. }\end{array}$ & 0.2388 & 0.426 \\
\hline Big city & $\begin{array}{l}=1 \text { if the adult lives in a town with more than } 400 \\
\text { thousand inhabitants; } 0 \text { otherwise. }\end{array}$ & 0.1500 & 0.357 \\
\hline Coast & Percentage of kilometers of coast in each Spanish region & 0.2910 & 0.228 \\
\hline Island residence & $=1$ if the adult lives in Balearic I. or in Canary I.; 0 otherwise. & 0.0918 & 0.275 \\
\hline
\end{tabular}

Note: mean and standard deviation computed using sampling weights. Source: own elaboration from the 2003 sample of SNHS (2003).

Cavelaars et al., 2000; Ezzati et al., 2006). A recent study concludes that while men tend to overestimate their reported height, women report their height quite accurately (Cizmecioglu et al., 2005). We restricted our sample to adult subjects to avoid potential biases resulting from the fact that younger individuals have not yet reached their final height (Persico et al., 2004). Though aware of the over-reporting problem, we decided not to correct our sample because we lack precise information on the magnitude of the bias. Moreover, we believe the bias to be a function of the covariates we control for.

Our original sample contained 21,045 adults aged 20-99 from all Spanish regions. Some 329 observations were, however, deleted due to missing data on height and 5320 observations were excluded because no data were available on relevant variables of interest in our investigation. 
Hence, the final sample includes 15,396 adults (6925 men and 8471 women). ${ }^{9}$ The reason for adding only subjects aged 20 and over rests in that height picks at that age. Table 1 reports the definition, mean and standard deviation of the variables used as determinants of height in the empirical analysis. Eight dichotomous birth cohort variables were defined in order to reflect birth cohort effects on individual height and to capture the exposure to different environmental factors at growing ages (Steckel, 1995). ${ }^{10}$ We expect to find that heights increased over time (Komlos and Kriwy, 2002).

One possible explanation for the differences in adult height is the difference in individual ability to produce health. Height is generally sensitive to socio-economic conditions (Persico et al., 2004; Komlos and Baur, 2004). Since earnings (i.e., total monthly net household income) are measured in the survey as a categorical variable with eight response categories, we first transformed income intervals into a continuous income variable by estimating an interval regression model using age, gender and professional status of the head of the household as main covariates. ${ }^{11}$ As it is common practice, education is taken as a measure of the individual's efficiency in health production (Kenkel, 1991) as well as a proxy of individual capabilities, we use educational attainment, defining four categories of education: unschooled and/or illiterate, primary education, secondary education and university education. Survey data has been commonly used to study a social gradient in height (Komlos and Kriwy, 2002).

We also explore the role played by nationality to explain differences in physical stature. Since we do not have information on ethnic groups, we grouped them by origin though we are aware that our database underestimates the number of non-nationals-as $97 \%$ of interviewees were Spanish (legal) nationals. This could imply that some omitted variable bias exists even if we control for them. In any case we re-estimate the models excluding immigrants in order to explore the sensitivity of the results.

In order to control for rural/urban height differences resulting from better access to health inputs, we define up to four dummy variables depending on the size of the interviewee's area of residence. Similarly, a dummy variable was included to capture the impact of insularity, that is, of living on an island (i.e., the Balearics or the Canaries) as opposed to living in the Iberian Peninsula, and another regional variable was considered in the model as control: the percentage of kilometers of shore in each region. An alternative regression specification was to include only dummy variables for region controls, but regional variables alone neither appeared nor were to pick up most of the geographical heterogeneity, and province level controls were not available.

\subsection{Quantile regression}

Traditionally, individuals' height has been assessed using ordinary least squares (OLS) or truncated regression. However, the method only provides information on the effects of variables

\footnotetext{
${ }^{9}$ Notwithstanding, we checked the completed sample (20,716 observations) and found that the characteristics of those individuals with missing values on income were roughly the same as those included in the final sample. Hence, no influence on potential sample selection was found.

${ }^{10}$ To carry out meaningful empirical analysis there must be a sizeable "control group". Here we have taken the generation born in 1930-1939 who was raised during Spanish Civil War (1936-1939).

${ }^{11}$ Interval regression converts the income categories into a continuous variable. Once net household income was derived, we divided it by an equivalence factor (the square root of the number of household members) to adjust for differences in household size and composition.
} 
on the mean height, although there may well be significant unobserved heterogeneity that must be controlled for, affecting the mean. To obtain this information, as Kan and Tsai (2004) did in a study of obesity, one can use a quantile regression (QR) framework (Koenker and Halloc, 2001). This technique allows us to measure the determinants of an individual's physical stature at different points of the height distribution.

The QR model specifies the conditional quantile as a linear function of covariates. Denoting individuals' height as $H_{i}$, the QR model to the $\theta$ th $(0<\theta<1)$ quantile can be expressed as: $H_{i}\left(\beta_{i}^{\prime} X_{i}\right)=\mu_{\theta i}$ where $\beta_{\theta i}$ is a vector of coefficients, $X_{i}$ a vector of economic determinants and $\mu_{\theta i}$ a random term, so that: $Q_{\theta}\left(H_{i} / X_{i}\right)=\beta_{\theta} X_{i}$ where $Q_{\theta}$ is the conditional quantile or the $\theta$ quantile of the height density conditional on $X_{i}$ and $\beta_{\theta k}$ refers to the marginal change in the $\theta$ th conditional quantile due to a change in $X_{i k}$. The standard errors from QR may be computed analytically and calculated using 'bootstrapping' methods (Koenker and Basset, 1978).

\subsection{Gender height gap decomposition}

To quantify the factors that explain gender differences in mean height, we follow the BlinderOaxaca linear decomposition procedure. The technique requires coefficient estimates from linear regressions and sample means of the covariates used in the regressions. We start with the following models: $H_{i}^{\mathrm{m}}=X_{i}^{\mathrm{m}} \beta^{\mathrm{m}}+\mu^{\mathrm{m}}$ and $H_{i}^{\mathrm{f}}=X_{i}^{\mathrm{f}} \beta^{\mathrm{f}}+\mu^{\mathrm{f}}$ where the ' $\mathrm{m}$ ' and 'f' subscripts refer to males and females respectively. Following the Blinder-Oaxaca decomposition, the average male/female height gap can be expressed as: $\bar{H}_{i}^{\mathrm{m}}-\bar{H}_{i}^{\mathrm{f}}=\left(\bar{X}_{i}^{\mathrm{m}}-\bar{X}_{i}^{\mathrm{f}}\right) \hat{\beta}^{\mathrm{m}}+\bar{X}_{i}^{\mathrm{f}}\left(\hat{\beta}^{\mathrm{m}}-\hat{\beta}^{\mathrm{f}}\right)$ where $\bar{H}^{\mathrm{j}}$ is the predicted mean value of height, $\bar{X}_{i}^{\mathrm{j}}$ is a row vector of average values of the independent variables and $\hat{\beta}^{j}$ is a vector of coefficient estimates for gender ' $j$ ' $(j=m, f)$. This allows us to decompose the influence of each of the factors included in our regression model on the difference in the outcome variable of interest. The first term in brackets in the last equation measures the portion of the gender gap that is due to group differences in the distribution of $X$ or differences in observed endowments ("the explained part"), while the second term reflects the portion of the gender gap attributed to differences in unmeasurable or unobserved endowments or characteristics ("the unexplained part").

Furthermore, given that gender differences might well be subjected to individual heterogeneity that is unobservable to the researcher, we use $\mathrm{QR}$ to examine whether extending the approach captures additional heterogeneity, following García et al. (2001). Accordingly, using a set of observable characteristics $X_{i}$, men and women's height can be compared at different quantiles, as follows: $\hat{Q}_{\theta}\left(H_{i}^{\mathrm{m}} / X_{i}\right)-\hat{Q}_{\theta}\left(H_{i}^{\mathrm{f}} / X_{i}\right)$. Hence, assuming that the $\theta$ th quantile of the error term is zero, it is then possible to estimate the predicted gender gap, as follows: $\hat{Q}_{\theta}\left(H_{i}^{\mathrm{m}} / X_{i}\right)-\hat{Q}_{\theta}\left(H_{i}^{\mathrm{f}} / X_{i}\right)=X_{i}\left(\hat{\beta}_{\theta}^{\mathrm{m}}-\hat{\beta}_{\theta}^{\mathrm{f}}\right)+\varepsilon$ where the choice of $X_{i}$ is arbitrary and so is the error term $(\varepsilon)$.

\section{Results}

\subsection{Preliminary evidence}

Fig. 1 reports adult heights by age groups for both men and women in 1993 and 2003 in Spain. The principal differences in adult height suggest the existence of a birth cohort effect among those younger than 60 among men and younger than 50 among women. That is, in general younger generations are systematically taller, which has to take into account that individuals 


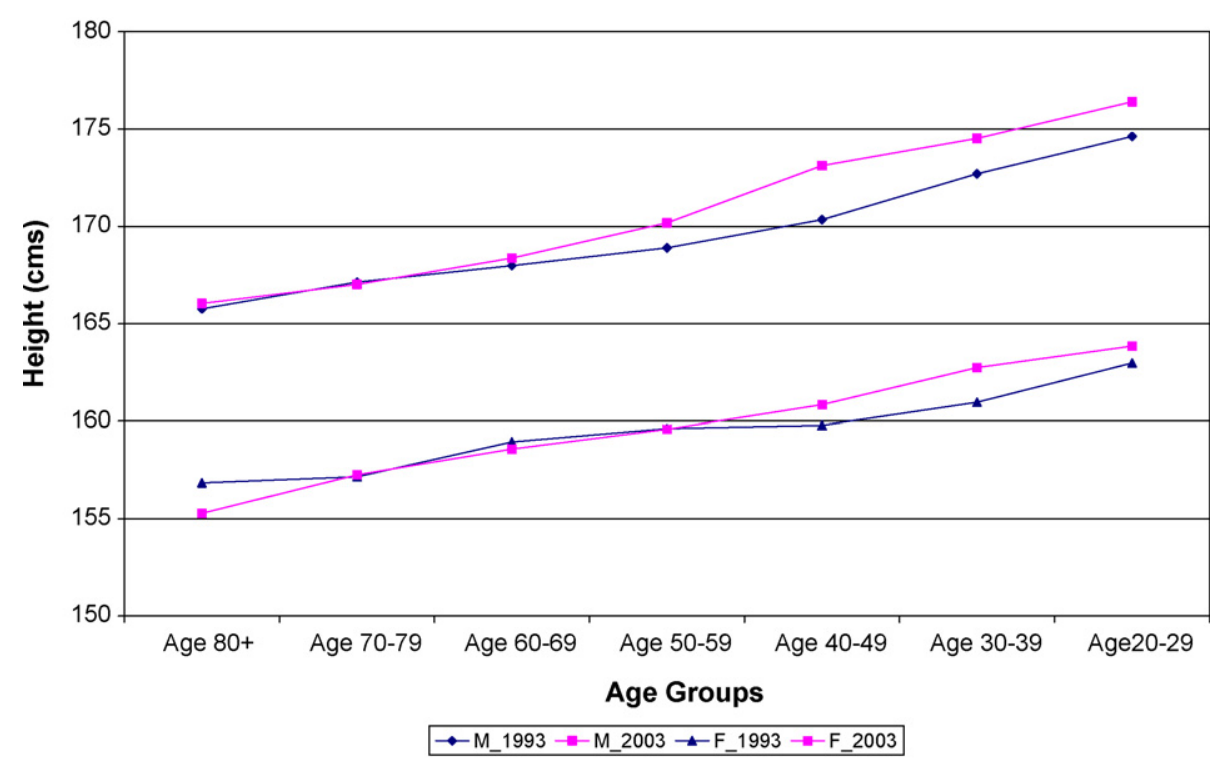

Source: Own elaboration from the 1993 and 2003 editions of the SNHS.

Fig. 1. Height by age profile and gender in Spain: 1993, 2003. Source: own elaboration from the 1993 and 2003 editions of the SNHS.

began to shrink at the age of 50. Indeed, the cross-cohort difference peaks at the ages of 40-49 for men and 30-39 for women.

Table 2 provides evidence on adult heights by using survey data from four selected sources (1993, 1997, 2001, and 2003). The table obviously indicates that height generally declines as individual's age and height increases specially for the youngest age groups of men over time.

Table 2

Mean height by gender and age groups in Spain: 1993-2003

\begin{tabular}{|c|c|c|c|c|c|c|c|c|c|}
\hline \multirow[t]{2}{*}{ Gender } & \multirow[t]{2}{*}{ Age group } & \multicolumn{2}{|l|}{2003} & \multicolumn{2}{|l|}{2001} & \multicolumn{2}{|l|}{1997} & \multicolumn{2}{|l|}{1993} \\
\hline & & Mean $(\mathrm{cm})$ & (S.E.) & Mean $(\mathrm{cm})$ & (S.E.) & Mean $(\mathrm{cm})$ & (S.E.) & Mean $(\mathrm{cm})$ & (S.E.) \\
\hline \multirow[t]{7}{*}{ Men } & $20-29$ & 176.40 & $(0.21)$ & 176.36 & $(0.17)$ & 175.59 & $(0.32)$ & 174.63 & $(0.165)$ \\
\hline & $30-39$ & 174.52 & $(0.17)$ & 174.37 & $(0.16)$ & 174.06 & (1.11) & 172.70 & (0.167) \\
\hline & $40-49$ & 173.13 & $(0.16)$ & 172.06 & $(0.19)$ & 170.69 & $(0.51)$ & 170.34 & $(0.175)$ \\
\hline & $50-59$ & 170.17 & $(0.20)$ & 170.00 & $(0.18)$ & 168.30 & $(0.45)$ & 168.89 & $(0.185)$ \\
\hline & $60-69$ & 168.37 & $(0.19)$ & 167.96 & $(0.22)$ & 168.40 & $(0.33)$ & 167.98 & (0.198) \\
\hline & $70-79$ & 167.01 & $(0.21)$ & 167.69 & $(0.26)$ & 166.67 & $(0.71)$ & 167.13 & $(0.295)$ \\
\hline & $>80$ & 166.03 & $(0.36)$ & 165.96 & $(0.48)$ & 167.11 & $(0.82)$ & 165.76 & $(0.663)$ \\
\hline \multirow[t]{7}{*}{ Women } & $20-29$ & 163.85 & $(0.18)$ & 163.92 & $(0.16)$ & 163.45 & $(0.33)$ & 162.97 & $(0.138)$ \\
\hline & $30-39$ & 162.73 & $(0.14)$ & 162.08 & $(0.17)$ & 160.76 & $(0.37)$ & 160.96 & $(0.148)$ \\
\hline & $40-49$ & 160.84 & $(0.15)$ & 160.04 & $(0.17)$ & 159.62 & $(0.47)$ & 159.78 & $(0.171)$ \\
\hline & $50-59$ & 159.59 & $(0.16)$ & 159.54 & $(0.18)$ & 159.40 & $(0.33)$ & 159.62 & $(0.173)$ \\
\hline & $60-69$ & 158.58 & $(0.15)$ & 158.56 & $(0.20)$ & 157.62 & $(0.51)$ & 158.94 & $(0.182)$ \\
\hline & $70-79$ & 157.26 & $(0.15)$ & 157.48 & $(0.26)$ & 157.77 & $(0.48)$ & 157.15 & $(0.273)$ \\
\hline & $>80$ & 155.28 & $(0.23)$ & 156.12 & $(0.47)$ & 157.90 & (1.09) & 156.84 & $(0.561)$ \\
\hline
\end{tabular}

Note: self-reported height in response to the following question: "What is your height without shoes in cms?" Source: Encuesta Nacional de Salud (Spanish National Health Survey), selected years. 
Descriptive evidence is consistent with mean height traditionally being low in Spain compared with rest of Europe.

\subsection{OLS results}

OLS parameter estimates of the determinants of (self-reported) adult height are displayed in Table 3, with the complete set of regressors (Eq. [1]) and excluding income (Eq. [2]) or nationality (Eq. [3]) as explanatory covariates to analyze their influence on the rest of the estimated coefficients. Robust standard errors and sampling weights were used in the estimation procedure. Estimates of the 'variance-inflation factors' for each covariate allow us to rule out the hypothesis of serious multicollinearity problems. $R^{2}$ values suggest that our specification already explains between 15 and $20 \%$ of the variability in height, suggesting that human height is influenced by environmental effects. The F-statistics suggest that the estimated parameters are jointly significant.

As Eq. [1] in Table 3 shows, we find significant and increasing birth cohort differences in height relative to the 1930s reference category. Difference in height between men born before the 1920s was negligible as compared to those born in the 1930s. Along with cohorts born in the 1920s and 1940s these are the groups that suffered the immediate consequences of the post-civil-war autarky. However, women born in the 1920s or before were smaller, a fact that may indicate improvements in gender equality in the Second Republic. It is worth to note the remarkable height increases registered by the Spanish population since the 1960s. For instance, while men (women) born in the 1950s were $2.5(1.2) \mathrm{cm}$ taller than individuals born in the 1930s, men (women) born in the 1980s who grew up in a democratic environment with self-fulfilling institutions such us the welfare state (the right to health and social care) were roughly 7 (5) $\mathrm{cm}$ taller than their counterparts born in the 1930s. Height increase is generally greater in men than in women, possibly due to the adverse socio-environmental conditions experienced by women.

As expected, we found a positive and statistically significant effect of ability on physical stature. Income elasticity of height is 0.004 for men and 0.003 for women, measured at the mean, indicating that doubling an individual's income produces a $0.4(0.3)$ percent increase in height. Our results also show that physical stature increases sharply with the level of education: men who have completed university education (secondary education) are 4.2 (3.1) $\mathrm{cm}$ taller than their unschooled or illiterate counterparts. The same applies to women, although the impact of education on height is smaller: women with university education (secondary education) are $3.2(2.4) \mathrm{cm}$ taller than unschooled or illiterate women. Overall, we conclude that the ability to produce health at younger ages - both due to existing endowments and as a result of parental influence (education) - is a positive and significant determinant of individual height. ${ }^{12}$ Notice that although in principle income in Eq. [1] is arguably endogenous, the Hausman's exogeneity test allows us to disregard this possibility and treat income as an exogenous covariate. Nonetheless, Eq. [2] of Table 3 shows very similar coefficient estimates of height determinants after dropping income effects from the model.

\footnotetext{
${ }^{12}$ Arguably, income here measures unobserved variables such as ability and innate skills, which for similar investments in human capital, allow individuals to obtain a larger pay off. As Case and Paxson (2006) argue, the association between income and height is quite likely to result from the existence of a third variable, such as individual capabilities. This is the interpretation that we apply to the significance of the variable income and education.
} 
Table 3

OLS estimations of adult height for men and women

\begin{tabular}{|c|c|c|c|c|c|c|}
\hline & \multicolumn{3}{|l|}{ Men } & \multicolumn{3}{|l|}{ Women } \\
\hline & Eq. [1] & Eq. [2] & Eq. [3] & Eq. [1] & Eq. [2] & Eq. [3] \\
\hline Constant & $165.43^{* *}$ & $165.94^{* *}$ & $165.47^{* *}$ & $156.19^{* *}$ & $156.67^{* *}$ & $156.29^{* * *}$ \\
\hline \multicolumn{7}{|l|}{ Birth cohort } \\
\hline$<1920$ & -0.419 & -0.333 & -0.451 & $-2.325^{* *}$ & $-2.281^{* *}$ & $-2.366^{* *}$ \\
\hline 1920-1929 & $-0.942^{*}$ & $-0.951^{*}$ & $-0.965^{*}$ & $-0.938^{* *}$ & $-0.941^{* *}$ & $-0.961^{* *}$ \\
\hline 1930-1939 & Ref. & Ref. & Ref. & Ref. & Ref. & Ref. \\
\hline 1940-1949 & $1.563^{* *}$ & $1.643^{* *}$ & $1.570^{* * *}$ & $0.845^{* *}$ & $0.903^{* *}$ & $0.835^{* *}$ \\
\hline 1950-1959 & $2.517^{* *}$ & $2.574^{* * *}$ & $2.533^{* *}$ & $1.191^{* *}$ & $1.227^{* *}$ & $1.217^{* * *}$ \\
\hline 1960-1969 & $4.574^{* * *}$ & $4.551^{* *}$ & $4.573^{* *}$ & $2.679^{* *}$ & $2.652^{* *}$ & $2.657^{* * *}$ \\
\hline 1970-1979 & $5.432^{* *}$ & $5.440^{* * *}$ & $5.389^{* * *}$ & $3.688^{* * *}$ & $3.582^{* *}$ & $3.651^{* *}$ \\
\hline 1980-1984 & $6.998^{* * *}$ & $6.935^{* *}$ & $7.004^{* *}$ & $5.018^{* *}$ & $4.862^{* *}$ & $4.984^{* *}$ \\
\hline \multicolumn{7}{|l|}{ Capabilities } \\
\hline Equivalent income & $0.001^{* *}$ & - & $0.001^{*}$ & $0.001^{* *}$ & - & $0.001^{* *}$ \\
\hline Unschooled & Ref. & Ref. & Ref. & Ref. & Ref. & Ref. \\
\hline Primary education & $1.240^{* *}$ & $1.336^{* *}$ & $1.214^{* *}$ & $1.747^{* *}$ & $1.866^{* *}$ & $1.679^{* *}$ \\
\hline Secondary education & $3.123^{* *}$ & $3.385^{* *}$ & $3.098^{* * *}$ & $2.356^{* *}$ & $2.651^{* * *}$ & $2.245^{* *}$ \\
\hline University education & $4.239^{* *}$ & $4.848^{* *}$ & $4.249^{* *}$ & $3.192^{* * *}$ & $3.793^{* *}$ & $3.107^{* *}$ \\
\hline \multicolumn{7}{|l|}{ Nationality and ethnicity } \\
\hline Spanish & Ref. & Ref. & Ref. & Ref. & Ref. & Ref. \\
\hline Euro-North American & $4.160^{* * *}$ & $4.227^{* *}$ & - & 1.344 & 1.357 & - \\
\hline South-American & -1.736 & $-1.868^{*}$ & - & $-3.314^{* *}$ & $-3.339^{* *}$ & - \\
\hline Asian-Oceania & -2.054 & -1.762 & - & -2.231 & -2.045 & - \\
\hline African & 3.454 & 3.316 & - & $4.048^{* * *}$ & $4.021^{*}$ & - \\
\hline \multicolumn{7}{|l|}{ Geographical controls } \\
\hline Village & Ref. & Ref. & Ref. & Ref. & Ref. & Ref. \\
\hline Town & 0.374 & 0.422 & 0.368 & -0.165 & -0.142 & -0.196 \\
\hline City & 0.551 & 0.617 & 0.538 & 0.201 & 0.233 & 0.179 \\
\hline Big city & 0.777 & $0.917^{*}$ & 0.722 & 0.272 & 0.389 & 0.193 \\
\hline Coast & 0.534 & 0.536 & 0.532 & 0.001 & -0.026 & -0.042 \\
\hline Island residence & 0.391 & 0.312 & 0.416 & $1.470^{* *}$ & $1.409^{* *}$ & $1.440^{* *}$ \\
\hline No. of obs. & 6925 & 6925 & 6925 & 8471 & 8471 & 8471 \\
\hline F-statistic & 54.83 & 56.24 & 66.18 & 48.68 & 50.95 & 58.47 \\
\hline$R^{2}$ (adjusted) & 0.200 & 0.197 & 0.196 & 0.157 & 0.154 & 0.151 \\
\hline
\end{tabular}

Note: OLS regression with robust standard errors and using sampling weights. Ref. means reference or omitted category. Source: own elaboration from the 2003 sample of the SNHS (2003). Adults are those aged 20 and over.

* Significant at $5 \%$ level.

** Significant at $1 \%$ level.

As expected, EU and North American men are significantly taller $(4.1 \mathrm{~cm})$, while SouthAmerican women are shorter $(3.3 \mathrm{~cm})$ than their Spanish counterparts. This result should be taken with caution given the low representativity of non-Spanish nationals in the sample. Only for control purposes we included in the regression lifestyle choices and geographical variables but were generally insignificant. For robustness purposes, we re-estimated the same height equation excluding nationality in an attempt to reduce individual heterogeneity (i.e., reducing sampling variability and sensitivity to unobserved bias) (Rosenbaum, 2005). As Eq. [3] in Table 3 reports, the impact on the determinants of height is negligible. 
Table 4

Quantile regression estimates of adult height for men

\begin{tabular}{|c|c|c|c|c|}
\hline & \multicolumn{4}{|c|}{ Dependent variable: height $(\mathrm{cm})$} \\
\hline & $10 \%$ & $25 \%$ & $75 \%$ & $90 \%$ \\
\hline Constant & $157.23^{* * *}$ & $160.09^{* *}$ & $169.05^{* *}$ & $173.55^{* *}$ \\
\hline \multicolumn{5}{|l|}{ Birth cohort } \\
\hline$<1920$ & -2.373 & -1.013 & 0.154 & 0.820 \\
\hline $1920-1929$ & $-2.831^{* *}$ & -0.933 & -0.123 & -0.033 \\
\hline 1930-1939 & Ref. & Ref. & Ref. & Ref. \\
\hline 1940-1949 & 0.464 & $1.330^{* * *}$ & $1.736^{* *}$ & $1.361^{*}$ \\
\hline $1950-1959$ & $1.124^{*}$ & $2.531^{* *}$ & $3.899^{* * *}$ & $3.794^{* *}$ \\
\hline $1960-1969$ & $3.300^{* *}$ & $4.461^{* *}$ & $6.041^{* *}$ & $5.477^{* *}$ \\
\hline 1970-1979 & $4.014^{* *}$ & $4.792^{* *}$ & $7.260^{* *}$ & $7.053^{* *}$ \\
\hline $1980-1984$ & $5.686^{* *}$ & $6.769^{* *}$ & $9.013^{* *}$ & $9.343^{* *}$ \\
\hline \multicolumn{5}{|l|}{ Capabilities } \\
\hline Equivalent income & $0.001^{* *}$ & $0.001^{* *}$ & $0.001^{* *}$ & 0.000 \\
\hline Unschooled & Ref. & Ref. & Ref. & Ref. \\
\hline Primary education & $1.376^{* *}$ & $2.292^{* *}$ & 0.526 & $1.210^{*}$ \\
\hline Secondary education & $3.523^{* *}$ & $4.090^{* * *}$ & $2.531^{* *}$ & $2.790^{* *}$ \\
\hline University education & $4.492^{* *}$ & $4.690^{* *}$ & $3.687^{* *}$ & $4.125^{* *}$ \\
\hline \multicolumn{5}{|l|}{ Nationality and ethnicity } \\
\hline Spanish & Ref. & Ref. & Ref. & Ref. \\
\hline Euro-North American & -0.511 & $4.124^{* *}$ & $3.933^{*}$ & $4.814^{*}$ \\
\hline South-American & -3.108 & -1.878 & $-3.571^{* *}$ & $-5.149^{* *}$ \\
\hline Asian-Oceania & -1.010 & 0.766 & 1.279 & 0.275 \\
\hline African & 0.237 & 0.370 & -1.764 & -3.199 \\
\hline \multicolumn{5}{|l|}{ Geographical controls } \\
\hline Village & Ref. & Ref. & Ref. & Ref. \\
\hline Town & 0.476 & 0.070 & 0.371 & $1.058^{*}$ \\
\hline City & $0.719^{*}$ & 0.298 & 0.404 & 0.466 \\
\hline Big city & 0.483 & 0.456 & 1.132 & $1.452^{*}$ \\
\hline Coast & $2.088^{* *}$ & 0.806 & 0.082 & 0.322 \\
\hline Island residence & 0.568 & 0.175 & $0.825^{*}$ & $1.749^{*}$ \\
\hline Pseudo $R^{2}$ & 0.135 & 0.129 & 0.139 & 0.113 \\
\hline
\end{tabular}

Note: bootstrapping methods have been applied to derive standard errors. The number of replications has been set to 100 . Ref. means reference or omitted category.

Source: own elaboration from the 2003 sample of the SNHS (2003).

* Significant at $5 \%$ level.

*** Significant at $1 \%$ level.

\subsection{Quantile regression results}

Tables 4 and 5 show the estimates for the conditional quantile functions on height for men and women, using the same specification above. ${ }^{13}$ Birth cohort effects reveal significant differences across the height distribution both for men and for women (Fig. 2). ${ }^{14}$ We find no differences in

\footnotetext{
${ }^{13}$ The variance-covariance matrix of the QR estimates is obtained via bootstrapping methods with 100 replications.

${ }^{14}$ Fig. 2 also reports OLS (mean) coefficients (from Eq. [3] in Table 3) for reference purposes.
} 
Table 5

Quantile regression estimates of adult height for women

\begin{tabular}{|c|c|c|c|c|}
\hline & \multicolumn{4}{|c|}{ Dependent variable: height $(\mathrm{cm})$} \\
\hline & $10 \%$ & $25 \%$ & $75 \%$ & $90 \%$ \\
\hline Constant & $149.17^{* *}$ & $152.30^{* *}$ & $159.78^{* *}$ & $163.61^{* * *}$ \\
\hline $\begin{array}{l}\text { Birth cohort } \\
<1920 \\
1920-1929 \\
1930-1939 \\
1940-1949 \\
1950-1959 \\
1960-1969 \\
1970-1979 \\
1980-1984\end{array}$ & $\begin{array}{l}-2.296^{*} \\
-0.188 \\
\text { Ref. } \\
0.481 \\
0.600 \\
3.398^{\text {** }} \\
4.132^{\text {** }} \\
5.318^{\text {** }}\end{array}$ & $\begin{array}{l}-3.799^{* *} \\
-2.752^{* *} \\
\text { Ref. } \\
0.627 \\
0.782 \\
2.518^{* *} \\
3.396^{* *} \\
4.417^{* *}\end{array}$ & $\begin{array}{l}-1.757^{* *} \\
-0.777 \\
\text { Ref. } \\
1.108^{*} \\
1.972^{* *} \\
3.216^{* *} \\
4.412^{* *} \\
5.981^{* *}\end{array}$ & $\begin{array}{l}-1.492^{*} \\
-0.812 \\
\text { Ref. } \\
0.634 \\
1.466^{* *} \\
2.968^{\text {** }} \\
4.258^{\text {** }} \\
5.533^{\text {** }}\end{array}$ \\
\hline $\begin{array}{l}\text { Capabilities } \\
\text { Equivalent income } \\
\text { Unschooled } \\
\text { Primary education } \\
\text { Secondary education } \\
\text { University education }\end{array}$ & $\begin{array}{l}0.001^{*} \\
\text { Ref. } \\
0.224 \\
0.648 \\
2.189^{* *}\end{array}$ & $\begin{array}{l}0.001^{* *} \\
\text { Ref. } \\
1.319^{* *} \\
2.221^{* *} \\
3.093^{* *}\end{array}$ & $\begin{array}{l}0.001^{* *} \\
\text { Ref. } \\
1.222^{* *} \\
2.077^{* *} \\
2.524^{* *}\end{array}$ & $\begin{array}{l}0.001^{\text {** }} \\
\text { Ref. } \\
1.318^{* *} \\
1.914^{\text {** }} \\
2.248^{\text {** }}\end{array}$ \\
\hline $\begin{array}{l}\text { Nationality and ethnicity } \\
\text { Spanish } \\
\text { Euro-North American } \\
\text { South-American } \\
\text { Asian-Oceania } \\
\text { African }\end{array}$ & $\begin{array}{l}\text { Ref. } \\
1.406 \\
-2.277 \\
-3.843 \\
5.049\end{array}$ & $\begin{array}{l}\text { Ref. } \\
1.608^{*} \\
-3.235^{* *} \\
-6.450 \\
3.448^{\text {** }}\end{array}$ & $\begin{array}{l}\text { Ref. } \\
1.407 \\
-2.510^{* *} \\
-3.948 \\
5.006\end{array}$ & $\begin{array}{l}\text { Ref. } \\
1.426 \\
-2.640^{\text {** }} \\
8.838 \\
6.012^{\text {** }}\end{array}$ \\
\hline $\begin{array}{l}\text { Geographical controls } \\
\text { Village } \\
\text { Town } \\
\text { City } \\
\text { Big city } \\
\text { Coast } \\
\text { Island residence }\end{array}$ & $\begin{array}{l}\text { Ref. } \\
-0.216 \\
-0.045 \\
-0.288 \\
0.804 \\
0.903\end{array}$ & $\begin{array}{l}\text { Ref. } \\
0.057 \\
-0.118 \\
-0.221 \\
1.027^{*} \\
1.981^{* *}\end{array}$ & $\begin{array}{l}\text { Ref. } \\
0.302 \\
0.534 \\
0.441 \\
0.050 \\
1.175^{* *}\end{array}$ & $\begin{array}{l}\text { Ref. } \\
0.449 \\
0.772^{*} \\
0.206 \\
0.308 \\
0.953^{*}\end{array}$ \\
\hline Pseudo $R^{2}$ & 0.076 & 0.097 & 0.0830 & 0.090 \\
\hline
\end{tabular}

Note: bootstrapping methods have been applied to derive standard errors. The number of replications has been set to 100 . Ref. means reference or omitted category.

Source: own elaboration from the 2003 sample of the SNHS (2003).

* Significant at $5 \%$ level.

*** Significant at $1 \%$ level.

height evaluated in the top quantiles (the tallest) between the reference group and the tallest born in the 1920s and before, but a negative effect for the height of the shortest. In the shortest quantile heights did not increase significantly in the 1940s or 1950s while in the top $25 \%$ as well as in the top $10 \%$ heights did increase significantly. Furthermore, the birth cohort effect is systematically greater for taller men, the difference being roughly double for the tallest compared with the shortest. For women, birth cohort effects point in the same direction. Whilst relatively shorter women born in the 1920s or before seem to exhibit below average height levels (compared with the reference group), height of women born in the 1940s and 1950s does not differ from the reference group. 
(a) Men

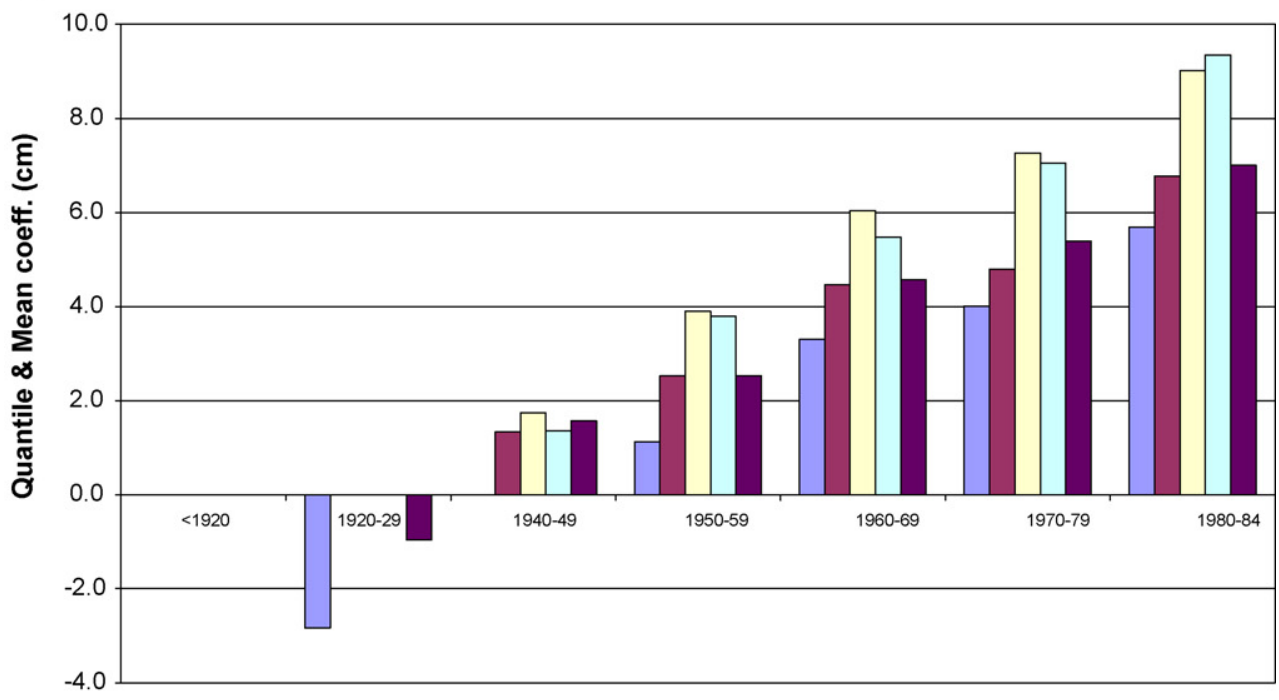

Bitrth cohorts

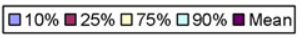

(b) Women

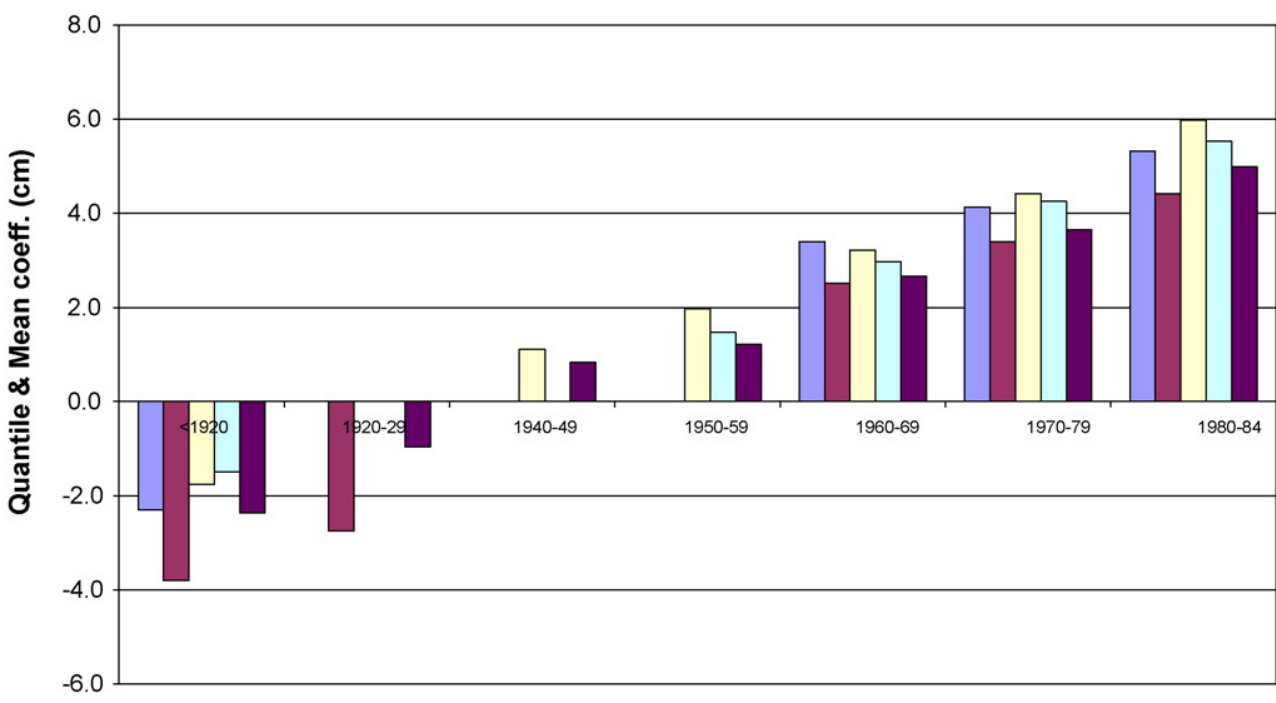

Birth cohorts

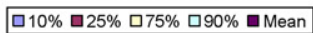

Fig. 2. Birth cohort effects across the height distribution (QR and mean coefficients). Note: only statistically significant mean and quantile regression coefficients for birth cohort effects from Tables 3 (Eq. [3]), 4 and 5 are plotted. Source: own elaboration from the 2003 sample of the SNHS (2003). 
Table 6

Blinder-Oaxaca decomposition of male and female adult's height dimorphism

\begin{tabular}{|c|c|c|}
\hline & \multicolumn{2}{|c|}{ Mean gender dimorphism in height $(\mathrm{cm})=11.741^{* *}$} \\
\hline & $\begin{array}{l}\text { Differences in mean characteristics } \\
\text { (explained part) }\end{array}$ & $\begin{array}{l}\text { Unexplained } \\
\text { (residual part) }\end{array}$ \\
\hline Birth cohort & $0.248(2.1 \%)$ & $1.203(10.2 \%)$ \\
\hline$<1920$ & 0.005 & $0.055^{*}$ \\
\hline $1920-1929$ & 0.017 & -0.000 \\
\hline $1930-1939$ & Ref. & Ref. \\
\hline 1940-1949 & 0.001 & 0.092 \\
\hline $1950-1959$ & $0.042^{*}$ & $0.204^{*}$ \\
\hline $1960-1969$ & $0.093^{*}$ & $0.374^{* *}$ \\
\hline $1970-1979$ & 0.057 & $0.359^{* *}$ \\
\hline $1980-1984$ & 0.033 & $0.119^{*}$ \\
\hline Capabilities & $0.250(2.1 \%)$ & $0.351(3.0 \%)$ \\
\hline Equivalent income & $0.039^{* *}$ & 0.065 \\
\hline Unschooled & Ref. & Ref. \\
\hline Primary education & -0.000 & -0.160 \\
\hline Secondary education & $0.125^{* *}$ & 0.239 \\
\hline University education & $0.086^{*}$ & 0.208 \\
\hline Nationality and ethnicity & $-0.001(-0.01 \%)$ & $0.051(0.44 \%)$ \\
\hline Spanish & Ref. & Ref. \\
\hline Euro-North American & -0.004 & 0.027 \\
\hline South-American & 0.003 & 0.027 \\
\hline Asian-Oceanian & -0.000 & -0.000 \\
\hline African & -0.001 & -0.003 \\
\hline Geographical controls & $-0.005(-0.04 \%)$ & $0.410(3.5 \%)$ \\
\hline Village & Ref. & Ref. \\
\hline Town & 0.005 & 0.188 \\
\hline City & -0.000 & 0.084 \\
\hline Big city & -0.010 & 0.079 \\
\hline Coast & -0.002 & 0.156 \\
\hline Island residence & 0.001 & $-0.097^{*}$ \\
\hline Constant & & $9.234(78.6 \%)$ \\
\hline Constant & & $9.234^{* * *}$ \\
\hline Total gap on height (in \%) & $0.492^{* *}(4.19 \%)$ & $11.249^{* *}(95.81 \%)$ \\
\hline
\end{tabular}

Note: linear decomposition based on female coefficients as reference. Ref. means reference or omitted category. Source: own elaboration from the 2003 sample of the SNHS (2003).

* Significant at $5 \%$ level.

** Significant at $1 \%$ level.

These results seem to suggest that people who were tall increased their advantage. Insofar as wealthier were taller-this implies that wealthier benefited more from the Franco regime, as well as from democratization. Inequality increased as a result. We find increase in men's heights at the right tail (tallest) of the distribution for those bon in the 1950s and 1960s still under the dictatorship. However, for those born 1970s and 1980s under (transition to) democracy we find that height grew especially among relatively shorter women (roughly $2.5 \mathrm{~cm}$ ) even more than it did for shorter men (roughly $1.5 \mathrm{~cm}$ ). For taller men and women the effect is similar (about $3 \mathrm{~cm}$ ). 
Table 7

Predicted and decomposition of the gender height dimorphism

\begin{tabular}{llllll}
\hline Quantile & Men height & $\begin{array}{l}\text { Women } \\
\text { height }\end{array}$ & $\begin{array}{l}\text { Total height } \\
\text { gap }\end{array}$ & $\begin{array}{l}\text { Explained } \\
\text { part }\end{array}$ & $\begin{array}{l}\text { Explained part/total } \\
\text { height gap (\%) }\end{array}$ \\
\hline 10th & 163.076 & 152.003 & 11.072 & 0.463 & 4.19 \\
25th & 166.922 & 155.679 & 11.242 & 0.650 & 5.78 \\
50th & 171.295 & 159.992 & 11.303 & 0.587 & 5.19 \\
75 th & 175.878 & 163.989 & 11.888 & 0.600 & 5.04 \\
90th & 180.476 & 167.643 & 12.833 & 0.557 & 4.34 \\
Mean & 172.436 & 160.695 & 11.741 & 0.492 & 4.19 \\
\hline
\end{tabular}

Note: linear decomposition based on female coefficients as reference. All these measures are statistically significant at 1\%. Source: own elaboration from the 2003 sample of the SNHS (2003).

Besides birth cohort effects, we find evidence of the effects of ability on adult height for both men and women. Yet, while income effects are relatively stable across the height distribution, the effects of education are greater among shorter individuals. These effects of education suggest that individuals more able to acquire knowledge tend to be growing faster, especially if they are relatively shorter. We find that educational ability is more important for women than for men. Regarding geographical controls, significant effects are found for men and women for residence on an island, which probably explains access to certain types of food, namely fish, and other related health inputs, namely more sunlight and less stress.

\subsection{Gender height dimorphism}

In our dataset the mean gender dimorphism in adult height was $11.74 \mathrm{~cm}$ (Table 6). After applying the Blinder-Oaxaca decomposition analysis on this mean differential and setting the female equation as a reference, we conclude that the explained portion or differences due to endowments or characteristics is very low $-4.2 \%$ - while the unexplained dimorphism is sizable, amounting to $96 \%$. This result shows unambiguously those unobservable factors such as genetic differences account for almost all of sexual dimorphism. ${ }^{15}$

However, this analysis considers only the information provided by conditional means, which may lead us to conclude that the size of the height dimorphism and the weights of the covariates that make it up are constant over the height distribution. As additional evidence, we use QR to decompose gender dimorphism. Table 7 presents the predicted height at the 10th, 25th, 50th, 75th and 90th quantiles of the height distribution conditioned on the vector of mean characteristics in the sample (García et al., 2001). The table also includes the gender height dimorphism computed from the QR estimates and the portion of the latter that can be explained by differences in average characteristics between men and women.

Note that the height dimorphism that the model predicts for individuals with the mean sample characteristics is greater at taller heights. The greatest dimorphism is found at the ninth decile $(12.83 \mathrm{~cm})$. However, note also that the "explained" height difference is roughly the same for in all quantiles, meaning that basically birth cohort and capabilities effects are relatively smaller for taller individuals.

\footnotetext{
${ }^{15}$ Results are roughly the same when the reference group is the male equation (data not shown).
} 


\section{Discussion}

This paper examines the time trend in human height for the Spanish adult population taking into account individual heterogeneity and a number of covariates in order to explore secular changes in health and the biological standard of living in Spain under different political regimes. It also explores gender dimorphism. We further find that these effects differ across genders and could explain part of the existing gender dimorphism in contemporary Spain. These results are consistent with the hypothesis of returns to institutional reforms that modify the health production and social environment rather than economic performance alone (North, 1989, 1990).

In the light of this study, the Spanish experience suggests two specific processes of height increase resulting from economic liberalization, in the first place, and especially from the inception of democracy. Furthermore, the convulsive decade of the 1930s with 3 years of Civil War and the post-war period seems to have exerted a brake on height increase. Given that some studies suggest that the period from birth to age three is generally identified as the post-natal period, that is, most critical to adult height, a war or the immediate post-war period may well have impeded access to the treatment and prevention of respiratory and other conditions. On the other hand, the personal and material misery that accompanies a conflict might have had a negative effect on the quality of parental care giving and on leading an autonomous life (Komlos et al., 1992).

Another relevant finding lies in that environmental (birth cohort) effects are different across the height distribution, so that generational effects are more intense among the tallest, and especially among taller men. Capabilities, measured by the specific ability to produce (selfreported) income and knowledge (educational attainment) lead to taller heights (Case and Paxson, 2006). That is, capabilities seem to explain individual's capacity to reach their greatest height potential, especially among shorter individuals. Nationality and geographical controls have a certain effect, but are heterogeneous across the height distribution. Thus, such effects indicate that there is some individual's heterogeneity that needs to be accounted for.

A third objective of this study referred to examining the influence of socio-political environment and individual heterogeneity in explaining patterns of gender dimorphism. Birth cohort effects and other controls explain only about $4 \%$ of the mean gender height dimorphism irrespective of the quantile evaluated.

Overall these results are consistent with the existence of gender-specific brakes that limit improvement in females' height resulting from environmental and gender-dependent effects. In the light of our results, we conclude that such environmental effects explain a small but significant percentage of gender dimorphisms (Bonduriansky, 2007). Environmental influences include the influence of sexist values that prevailed in the Spanish society until the late 1970s. Examples of women's dependence on men at the time were reflected in the absence of full civil liberties (such as the right to sell property) until the reform of the Civil Code after the end of the Franco dictatorship. Other explanations are sexist stereotypes given that girls did not enjoy the same rights as boys at school, being unable to make free choices regarding their basic education, social life, behavior as well as gender differences in economic and social participation that constrain women's well-being (Sen, 1999). Women also suffer more limited access to literacy and education (Klasen, 2002), and are more vulnerable to forms of physical and psychological violence (National Organization for Women, 2005). This complex problem has social and cultural ramifications, which may stigmatize women or even lead to gender-driven assaults that often go unreported, or child abuse. Spain comes 27 th out of 58 countries rated in terms of gender gap rankings, performing well on the dimensions of health and well being (reaching 5th place in this classification) and relatively poorly in education (34th) and economic participation (45th) 
(Lopez-Claros and Zahidi, 2005). Our results, therefore, confirm that the conditional mean estimates of height fail to fully represent the pattern of differences encountered throughout the height distribution.

Finally, it is important to stress that our study focuses exclusively on evidence from Spain, and the institutional and environmental effects which may be well country-specific. Countries that have experienced process of significant political transformation are ideal candidates for such types of studies. Primarily, it is difficult to disentangle cohort and political climate effects as the political changes cannot be thought of exerting immediate effects, and translate in reforms that make themselves felt in the long run. However, future research may provide additional insights into these questions, especially to the determinants of the rate of height evolution resulting form socio-economic reform processes and sexual dimorphism.

\section{Acknowledgements}

We are grateful to the comments of the journal anonymous referees but especially the amendments and suggestions from John Komlos. We also thank Joerg Baten, Jean Pascal Bassino, Arantxa Colchero, Nikola Koepke, Stephen. L. Morgan and participants at the Third International Conference on Economics and Human Biology, Strasbourg June 2006, for their comments and feedback. This study was supported by the Ministry of Education (Grant number: CICYT SEJ2005-06270) and the Generalitat de Catalunya (Grant number: 2005-SGR-460) and the XREPP - Xarxa de Referència en Economia i Políques Públiques.

\section{References}

Bogin, B., 1999. Patterns of Human Growth. Cambridge University Press, Cambridge.

Bonduriansky, R., 2007. The evolution of condition-dependent sexual dimorphism. Am. Nat. 169, 9-19.

Case, A., Paxson, C., 2006. Stature and status: height, ability, and labour market outcomes. NBER Working Paper No. 12466.

Cavelaars, A.E.J.M., Kunst, A.E., Geurts, J.J.M., Crialesi, R., Grotvedt, L., Helmert, U., Lahelma, E., Lundberg, O., Mielck, A., Rasmussen, N., Regidor, E., Sphuler, Th., Mackenbach, J.P., 2000. Persisting variations in average height between countries and between socio-economic groups: an overview of 10 European countries. Ann. Hum. Biol. 27, 407-421.

Cizmecioglu, F., Doherty, A., Paterson, W.F., Young, D., Donaldson, M.D.C., 2005. Measured versus reported parental height. Archiv. Dis. Childhood 90, 941-942.

Darwin, C.R., 1871. The Descent of Man, and Selection in Relation to Sex, first ed. John Murray, London.

Duran, A., Lara, J.J., van Waveren, M., 2006. Spain, health system review. Health Syst. Trans. 8, 1-208.

Ezzati, M., Martin, H., Skjold, S., vander Hoorn, S., Murray, C.J.L., 2006. Trends in national and state-level obesity in the USA after correction for self-reported bias: analysis of health surveys. J. Roy. Soc. Med. 99, 250-257.

Frieze, I.H., Olson, J.E., Good, D.C., 1990. Perceived and actual discrimination in the salaries of male and female managers. J. Appl. Soc. Psychol. 20, 46-67.

García Delgado, J.L., Jiménez, J.C., 1999. Un Siglo de España. In: La Economía, Marcial Pons, Madrid.

García, J., Hernández, P., López, A., 2001. How wide is the gap? An investigation of gender wage differences using quantile regression. Emp. Econ. 26, 149-168.

Giles, E., Hutchinson, D.L., 1991. Stature and age-related bias in self-reported stature. J. For. Sci. 36, 765-780.

Hill, A., Roberts, J., 1998. Body mass index: a comparison between self-reported and measured height and weight. J. Pub. Health Med. 20, 206-210.

Iversen, V., 2003. Intra-household inequality: a challenge for the capability approach? Fem. Econ. 9, 93-115.

Kan, K., Tsai, W.D., 2004. Obesity and risk knowledge. J. Health Econ. 23, 907-934.

Kenkel, D.S., 1991. Health behaviour, health knowledge and schooling. J. Pol. Econ. 99 (2), 287-305.

Klasen, S., 2002. Low schooling for girls, slower growth for All? Cross-country evidence on the effect of gender inequality in education on economic development. World Bank Econ. Rev. 16, 345-373. 
Komlos, J., Baten, J., 1998. The Biological Standard of Living in Comparative Perspective. Franz Steiner Verlag, Stuttgart.

Komlos, J., Kriwy, P., 2002. Social status and adult heights in the two Germanys. Ann. Hum. Biol. 29, 641-648.

Komlos, J., Baur, J., 2004. From the tallest to (one of) the fattest: the enigmatic fate of the American population in the 20th century. Econ. Hum. Biol. 2, 57-74.

Komlos, J., Lauderale, B.E., 2007. Underperformance in affluence: The remarkable relative decline in U.S. heights in the second half of the 20th Century. Soc. Sci. Quart. 88, 283-305.

Komlos, J., Tanner, J.M., Davies, P.S.W., Cole, T., 1992. The growth of boys in the Stuttgart Carlschule, 1771-93. Ann. Hum. Biol. 19, 139-152.

Koenker, R., Halloc, K.F., 2001. Quantile regression. J. Econ. Persp. 15, 143-156.

Koenker, R., Basset, G., 1978. Regression quantiles. Econometrica 46, 33-50.

López-Casasnovas, G., Costa-Font, J., Planas, I., 2005. Diversity and regional inequalities: assessing the outcomes of the Spanish system of health care services. Health Econ. 14, S221-S235.

Lopez-Claros, A., Zahidi, S., 2005. Women's Empowerment: Measuring the Global Gender Gap. World Economic Forum, Geneva.

National Organization for Women, 2005. 10 for Change. (available at http://www.10forchange.org/issues/violence brief.pdf, visited October 2006).

North, D.C., 1989. Institutions and economic growth: an historical introduction. World Dev. 17, 1319-1332.

North, D.C., 1990. A transaction cost theory of politics. J. Theo. Pol. 2, 355-367.

North, D.C., 1991. Institutions. J. Econ. Persp. 5 (1), 97-112.

Nussbaum, M.C., 2004. Hiding from Humanity: Disgust, Shame and the Law. Princeton University Press, Princeton.

Nussbaum, M.C., 2003. Capabilities as fundamental entitlements: sen and social justice. Fem. Econ. 9, 33-59.

Olson, M., 1993. Dictatorship, democracy and development. Am. Pol. Sci. Rev. 87, 567-576.

Persico, N., Postlewaite, A., Silverman, D., 2004. The effect of adolescent experience on labour market outcomes: the case of height. J. Pol. Econ. 2004 (112), 1019-1053.

Prados, L., 2006. Assessing economic progress in Spain 1850-2000. In: International Economic History Association Congress, Helsinki, August 20-26.

Rogers, A.R., Mukherjee, A., 1992. Quantitative genetics of sexual dimorphism in human body size. Evolution 46, 26334.

Rosenbaum, P.R., 2005. Heterogeneity and causality: unit heterogeneity and design in observational studies. Am. Stat. 59 (2), 147-152.

Sen, A., 1999. Development as Freedom. Oxford University Press, Oxford.

Silventoinen, K., 2003. Determinants of variation in adult body height. J. Biosoc. Sci. 35, 263-285.

Smith, P.K., Bogin, B., Varela-Silva, M.L., Loucky, J., 2003. Economic and anthropological assessments of the health of children in Maya immigrant families in the US. Econ. Hum. Biol. 1, 145-160.

Steckel, R.H., 1995. Stature and the standard of living. J. Econ. Lit. 33, 1903-1940.

Sunder, M., 2003. The making of giants in a welfare state: the Norwegian experience in the 20th century. Econ. Hum. Biol. $1,267-276$.

Tavares, J., Wacziarg, R., 2001. How democracy affects growth. Eur. Econ. Rev. 45 (8), 1341-1347.

Wolf, L.D., Gray, J.P., 1982. Latitude and intersocietal variation of human sexual dimorphism of stature. Hum. Ecol. 10 (3), 409-416.

World Health Organization (WHO), 1983. Measuring Change in Nutritional Status: Guidelines for Assessing the Nutritional Impact of Supplementary Feeding Programmes for Vulnerable Groups. WHO, Geneva. 